\title{
NEUTRON SCATTERING CHARACTERIZATION OF HOMOPOLYMERS AND GRAFT-COPOLYMER MICELLES IN SUPERCRITICAL CARBON DIOXIDE
}

D. Chillura-Martino and R. Triolo

Dipartimento di Chimica Fisica, University of Palermo

90123 Palermo, Italy

J. B. McClain, J. Combes, D. Betts, D. Canelas,

E. T. Samulski and J. M. DeSimone

Department of Chemistry, University of North Carolina

Chapel Hill, NC 27599-3290

H.D. Cochran, J. D. Londono and G. D. Wignall

Oak Ridge National Laboratory*

Oak Ridge, TN 37831-6393

\section{ABSTRACT}

Supercritical fluids are becoming an attractive alternative to the liquid solvents traditionally used as polymerization media ${ }^{1}$. As the synthesis proceeds, a wide range of colloidal aggregates form, but there has hitherto been no way to measure such structures directly. We have applied small-angle neutron scattering (SANS) to characterize such systems, and although SCF polymerizations are carried out at high pressures, the penetrating power of the neutron beam means that typical cell windows are virtually transparent. Systems studied include molecules soluble in $\mathrm{CO}_{2}$ (e.g. polyfluoro-octyl acrylate or PFOA) and this polymer has previously ${ }^{2}$ been shown to exhibit a positive second virial coefficient $\left(\mathrm{A}_{2}\right)$. Other $\mathrm{CO}_{2}$-soluble polymers include hexafluoro-polypropylene oxide (HFPPO), which appears to have a second virial coefficient which is close to zero $\left(10^{4} \mathrm{~A}_{2} \simeq 0 \pm 0.2 \mathrm{~cm}^{3} \mathrm{~g}^{-2} \mathrm{~mol}\right)$. Polydimethylsiloxane (PDMS), is soluble on the molecular level only in the limit of dilute solution and seems to form aggregates as the concentration increases $\left(c>0.01 \mathrm{~g} \mathrm{~cm}^{-3}\right)$. Other polymers (e.g. polystyrene) are insoluble in $\mathrm{CO}_{2}$, though polymerizations may be accomplished via the use of PS-PFOA blockcopolymer stabilizers, which are also amenable to SANS characterization, and have been shown ${ }^{3}$ to form micelles in $\mathrm{CO}_{2}$. Other amphiphilic surfactant molecules that form micelles include PFOA-polyethylene oxide (PFOA-PEO) graft copolymers, which swell as the $\mathrm{CO}_{2}$ medium is saturated with water. These systems have been characterized by SANS, by taking advantage of the different contrast options afforded by substituting $\mathrm{D}_{2} \mathrm{O}$ for $\mathrm{H}_{2} \mathrm{O}$. This paper illustrates the utility of SANS to measure molecular dimensions, thermodynamic variables, molecular weights, micelle structures etc. in supercritical $\mathrm{CO}_{2}$.

Submitted to the Journal of Molecular Structure (Special Issue containing the Proceedings of "Horizons in Small Angle Scattering from Mesoscopic Systems" (Stromboli, Italy, September 27-30, 1995).

The submitted manuscript has been authored by a contrector of the U.S. Government under contract No. DEACO5-840R2 1400. Accordingly. the U.S. Government retains a nonaxchusive, coyelty-freo biconse to publish or reproduce the published form of this contribution. or allow others to do so, for U.S. Goverrment purposes." 


\section{DISCLAIMER}

This report was prepared as an account of work sponsored by an agency of the United States Government. Neither the United States Government nor any agency thereof, nor any of their employees, makes any warranty, express or implied, or assumes any legal liability or responsibility for the accuracy, completeness, or usefulness of any information, apparatus, product, or process disclosed, or represents that its use would not infringe privately owned rights. Reference herein to any specific commercial product, process, or service by trade name, trademark, manufacturer, or otherwise does not necessarily constitute or imply its endorsement, recommendation, or favoring by the United States Government or any agency thereof. The views and opinions of authors expressed herein do not necessarily state or reflect those of the United States Government or any agency thereof. 


\section{INTRODUCTION}

Supercritical $\mathrm{CO}_{2}$ presents an environmentally benign medium for polymerizations which minimizes the production of organic solvent and aqueous waste and facilitates isolation of the polymer product ${ }^{1,46}$. However, only two classes of polymeric materials have been shown to exhibit appreciable solubility at readily accessible temperatures and pressures: amorphous fluoropolymers and silicones. Thus, the relative insolubility of many industrially important polymers in supercritical $\mathrm{CO}_{2}$ necessitates the use of heterogeneous polymerization techniques which employ stabilizing moieties to synthesize high molecular weight hydrocarbon polymers. The first successful dispersion polymerization in supercritical $\mathrm{CO}_{2}$ involved the stabilization of poly(methyl methacrylate) particles by the homopolymer poly(1,1-dihydroperfluorooctylacrylate) (PFOA) ${ }^{5}$. In order to allow the synthesis of other polymers which are relatively insoluble in $\mathrm{CO}_{2}$ (e.g. polystyrene), diblock copolymers have been synthesized for use as emulsifying agents in heterogeneous polymerizations. Because of their amphiphilic character, these stabilizers form micelles ${ }^{2}$, which promote the polymerization of styrene and give rise to spherical particles in quantitative yields ( $>90$ percent) in $\mathrm{CO}_{2}$.

Small angle neutron and $\mathrm{x}$-ray scattering (SANS and SAXS) methods allow the elucidation of the size and shape of both single polymer chains and supramolecular structures $^{7}$, and over the past two decades, SANS has emerged as the most powerful technique for studying polymer phase behavior ${ }^{8}$ and the self assembly of amphiphiles in aqueous media, ${ }^{9,10}$ in the resolution range 5-2000 $\AA$. The first experiments to apply these techniques to study polymers in supercritical $\mathrm{CO}_{2}$ have recently been undertaken ${ }^{2,3,11-13}$, 
and in this publication we review some of the first SANS data that have been taken to probe $\mathrm{CO}_{2}$-soluble polymers and also to characterize of the micellar structures formed by amphiphilic molecules.

\section{EXPERIMENTAL}

The experiments were performed on the W. C. Koehler $30 \mathrm{~m}$ SANS facility at the Oak Ridge National Laboratory ${ }^{14}$. The incident wavelength was $\lambda=4.75 \AA(\Delta \lambda / \lambda \sim 5 \%)$ and several sample-detector distances were used to give a range of momentum transfer, $0.005<\mathrm{Q}=4 \pi \lambda^{-1} \sin \theta<0.2 \AA^{-1}$, where $2 \theta$ is the angle of scatter. The procedures used to correct for detector efficiency, instrumental backgrounds are described elsewhere ${ }^{14,15}$. The neutror intensities were converted to an absolute $( \pm 3 \%)$ differential cross section per unit sample volume $\left[\mathrm{d} \Sigma / \mathrm{d} \Omega(\mathrm{Q})\right.$, in units of $\left.\mathrm{cm}^{-1}\right]$ by comparison with pre-calibrated secondary standards ${ }^{15}$. The cross section of the corresponding "blank" cell filled with $\mathrm{CO}_{2}$ formed only a minor correction to the "sample" data. The $\mathrm{CO}_{2}$ cross section [fig. (1)] results from density fluctuations near the critical point ${ }^{16}$, and amounts to $\sim 0.04 \mathrm{~cm}^{-1}$, at the lowest Q-values, with a slight angular dependence which reflects the size of the density fluctuations ( 5-10 $\AA$ ). The experiments were conducted in the same cell that has been used extensively for polymer synthesis ${ }^{1,4,5}$, and due to the high penetrating power of neutrons, the beam passed through two $1 \mathrm{~cm}$. sapphire windows, with virtually no attenuation (cell transmission $\simeq 93 \%$ ) or parasitic scattering. RESULTS AND DISCUSSION (1): $\mathrm{CO}_{2}$-SOLUBLE POLYMERS

For a homogenous polymer solution the methodology to extract the $R_{\mathfrak{g}}$, the radius of gyration (i.e. the r.m.s. distance of scattering elements from the center of gravity) and 
the second virial coefficient $\left(A_{2}\right)$, which indicates whether a polymer chain swells or contracts in the presence of a solvent is well established ${ }^{3,8,17}$. These parameters are related to the cross section via

$$
K c\left[\frac{d \Sigma}{d \Omega}(0)\right]^{-1}=\frac{1}{M_{w}}+2 A_{2} c
$$

where $A_{2}$ the second virial coefficient, $M_{w}$ is the (weight-averaged) molecular weight (MW), $\mathrm{c}$ is the concentration $\left.(\mathrm{g} \mathrm{cm})^{-3}\right)$ and $\mathrm{K}=[\Delta(\mathrm{SLD})]^{2} / \rho_{\mathrm{p}}{ }^{2} \mathrm{~A}_{\mathrm{o}}$ is the contrast factor for neutron scattering. $A_{0}$ is Avogadro's number, $\rho_{\mathrm{p}}$ is the polymer density and we have assumed initially that the volume from which $\mathrm{CO}_{2}$ is excluded by a PFOA chain in the supercritical fluid is the same as the molecular volume in the solid state. The factor in square brackets is the scattering length density (SLD) difference between PFOA (SLD = $0.0336 \times 10^{12} \mathrm{~cm}^{-2}$ in the solid state) and $\mathrm{CO}_{2}\left(\mathrm{SLD}=2.498 \rho_{\mathrm{CO} 2} \times 10^{12} \mathrm{~cm}^{-2}\right)$, giving $\mathrm{K}=$ $7.5 \times 10^{-5} \mathrm{~mol} \mathrm{~cm}^{2} \mathrm{~g}^{-2}$ at $\mathrm{T}=65^{\circ} \mathrm{C}$ and $\mathrm{P}=340 \mathrm{bar}$. SANS has previously been used ${ }^{3}$ to measure $\mathrm{A}_{2}$ and $\mathrm{MW}$ in the ranges $0.6<10^{4} \mathrm{~A}_{2}<0.25$ and $114<10^{-3} \mathrm{MW}<1000$. To our knowledge, small angle scattering is the only method currently available for molecular weight determination in supercritical fluids.

The polymer chain dimensions were derived from the measured cross sections using both the Zimm approach (for the low-Q data points) and also by fitting the data to a Debye random coil model ${ }^{8}$. Good agreement $( \pm 5 \%)$ was achieved between the two approaches [fig. (2)], and as the pressure is reduced the solubility decreases. At $T=65^{\circ}$ PFOA falls out of solution [fig. (3)] at the critical point ( $P=4350$ psi, or 296 bar) as indicated by a zero intercept on the ordinate $[\mathrm{d} \Sigma / \mathrm{d} \Omega(0) \rightarrow \infty]$. 
The values of $R_{g}$ are a function of molecular weight and may be summarized as $R_{g}=$ $(0.10 \pm 0.02) \mathrm{M}_{\mathrm{w}}{ }^{0.5}$. The second virial coefficient decreases with molecular weight, as is generally observed for polymer solutions, where $A_{2}\left(M_{w}\right)$ is empirically described by $A_{2}$ $\sim \mathrm{M}_{\mathrm{w}}^{-\delta}$, with $\delta \simeq 0.3$ in various systems ${ }^{18}$. From the two data points shown in Table (1) the exponent is $\delta=0.4$ for PFOA in supercritical $\mathrm{CO}_{2}$, showing that the variation of $A_{2}$ with $M_{w}$ is reasonable, as the error in $\delta$ is probably \pm 0.1 . These results indicate that transport of monomers or initiators to the inside of the PFOA chains or aggregates would occur more efficiently for the low molecular weight polymer, for which $A_{2}$ is larger and hence the chains are more swollen than for high MWs.

It has been demonstrated ${ }^{4}$ that PFOA can be used as a surface active agent to synthesize polymers that are otherwise insoluble in $\mathrm{CO}_{2}$ (e.g. polymethylmethacrylate) and hence it is important to understand how the addition of methylmethacrylate (MMA) monomer to the $\mathrm{CO}_{2}$ solvent affects the solution properties of PFOA. Initial studies indicate that the addition of 20 vol\% (liquid) $M M A$ to $\mathrm{CO}_{2}$ (at $\mathrm{T}=65^{\circ}$ and $\mathrm{P}=340$ bar) leads to a concentration of 12 mole $\%$, which increases the second virial coefficient by $\sim 350 \%$. The reason for this increase is not understood, as presumably, $A_{2}$ will decrease for higher concentrations of added MMA. Measurements are currently in progress to explore the effect of added monomer in more detail.

Fig. 4(a) shows a plot of $\mathrm{Kc}[\mathrm{d} \Sigma / \mathrm{d} \Omega(0)]^{-1}$ vs $\mathrm{c}$ for hexafluoropropylene-oxide (HFPPO) or Krytox ${ }^{\mathrm{TM}}$ and the values of $\mathrm{A}_{2}$ and $\mathrm{M}_{\mathrm{w}}$ are compared to the equivalent quantities for PFOA in Table 1. The magnitude of $\mathrm{M}_{\mathrm{w}}$ measured by SANS is in good agreement with the nominal MW given by the manufacturer (16k) and $\mathrm{A}_{2}$ is zero within the experimental 
error, indicating that the polymer coil adopts the unperturbed chain dimensions in $\mathrm{CO}_{2}$. Fig. 4(b) [plotting $\log _{10}\left(R_{\mathrm{g}}\right)$ vs. $\log _{10}(C)$ ], shows. that the observed variation in $R_{g}$ with concentration is systematic $\left(R_{\mathrm{g}} \sim c^{0.16}\right)$. For $0.02<c<0.093$, values of $R_{\mathrm{g}}$ are in the range $30-37 \AA$, giving $R_{g} / M_{w}^{0.5} \sim 0.29$, compared to 0.45 for polyethylene, 0.39 for polyethylene oxide and 0.35 for polypropylene. Thus, the size of a molecule for a given molecular weight becomes smaller as the size of the pendant group increases. The reason for the concentration dependence of $R_{g}$ is not understood at present.

For polydimethylsiloxane (PDMS) in $\mathrm{CO}_{2}$, fig (5) shows $\mathrm{Kc}[\mathrm{d} \Sigma / \mathrm{d} \Omega(0)]^{-1}$ vs. concentration at $\mathrm{T}=65^{\circ} \mathrm{C}$ and $\mathrm{P}=340$ bar. Above $c \simeq 0.02 \mathrm{~g} \mathrm{~cm}^{-3}$, both $\mathrm{d} \Sigma / \mathrm{d} \Omega(0)$ and $\mathrm{R}_{\mathrm{g}}$ increase disproportionately with concentration and similar behavior is exhibited at $\mathrm{T}=40^{\circ} \mathrm{C}$. For molecules of this size $(\mathrm{MW} \simeq 13 \mathrm{k})$, the intercept in fig. (3) should be $\sim 73$, indicating that there may already be some aggregation except possibly in the limit of infinite dilution $\left(\mathrm{c}<0.01 \mathrm{~g} \mathrm{~cm}^{-3}\right.$ ). In this event, the SANS data do not yield accurate values of $A_{2}$ or $M_{w}$.

Thus, for the three species of " $\mathrm{CO}_{2}$-soluble" molecules studied, $\mathrm{CO}_{2}$ appears to be either a "good" solvent (PFOA), a theta solvent (HFPPO) or a "poor" solvent (PDMS). RESULTS AND DISCUSSION (2): GRAFT COPOLYMER MICELLES

The first study of aggregation mechanisms of copolymer micelles in $\mathrm{CO}_{2}$ was undertaken by Fulton and coworkers ${ }^{11}$ on water-swollen PFOA-polyethylene oxide (PFOA-g-PEO) graft copolymers using SAXS, which was fitted to a core-shell model with inner and outer radii of 105 and $125 \AA$ respectively. The data were recorded in arbitrary, as opposed to absolute, units and thus it is possible that this model may be 
consistent with the shape of the data without reproducing the intensity ${ }^{15,18}$. We have therefore repeated these measurements via SANS using absolute units, and taken advantage of the contrast opportunities afforded by substituting $\mathrm{D}_{2} \mathrm{O}$ for $\mathrm{H}_{2} \mathrm{O}$. It will be seen that this allows a more stringent test of the model dimensions, though fortunately it does not alter the overall conciusions of the previous study. We have also examined this material in the absence of added water to show that the micelle dimensions are much larger in the presence of $\mathrm{H}_{2} \mathrm{O}$ swelling.

The synthesis of the PFOA-g-PEO material has been described elsewhere ${ }^{11}$, and the PEO grafts had a $M W \simeq 5000$, with 3-5 grafts per chain and a wt. fraction of PEO is in the range $15-18 \%$. Thus, the overall $\mathrm{MW}$ is estimated to be in the range $100-160 \mathrm{k}$. Fig. (6) shows the dramatic differences in the SANS data introduced by $\mathrm{H}_{2} \mathrm{O}$ and $\mathrm{D}_{2} \mathrm{O}$ swelling, as the radius of gyration increases from $\sim 56 \AA$ to $\sim 82 \AA\left(\mathrm{H}_{2} \mathrm{O}\right.$-swollen) and $136 \AA\left(\mathrm{D}_{2} \mathrm{O}-\right.$ swollen).

The SANS data were modelled as described previously ${ }^{9,10}$, and the micellar solutions are represented as a two phase system in which core-shell micelles interact in a solvent medium. For a collection of polydisperse particles, assuming no orientational correlations the coherent differential scattering cross section is given by

$$
\frac{d \sigma}{d \Omega}=N_{p}\left[\left\langle|F(Q)|^{2}\right\rangle+|\langle F(Q)\rangle|^{2}(S(Q)-1)\right]+B
$$

where $N_{p}$ is the number density of particles, $S(Q)$ is the structure function arising from interparticle scattering and $\mathrm{B}$ is the coherent background from $\mathrm{CO}_{2}$ [fig. (1)]. For the dilute solutions (e.g. $c<2 \% \mathrm{w} / \mathrm{v}$ ) considered here, interparticle interactions may be 
neglected, and the interparticle structure function in this case is similar to that of a dilute monatomic gas $(S(Q) \simeq 1)$. Spherical particles. with a centrosymmetric distribution of scattering length density may be modelled by a set of concentric spherical shells ${ }^{9,10}$, and for a core/shell micelle the intraparticle term in Equation (2) may be expressed as,

$$
\left\langle|F(Q)|^{2}\right\rangle=\int\left|F\left(Q, R_{1}\right)\right|^{2} f\left(R_{1}\right) d R_{1}
$$

Where $R_{1}$ is the radius of a core, which occurs within the distribution of core radii with a normalized frequency of $f\left(R_{1}\right)$. The structure function of a particle with core radius $R_{1}$ and outer radius $R_{2}$ is given by,

$$
\begin{aligned}
F(Q, R) & =\frac{4 \pi}{3}\left[R_{1}^{3}\left(\rho_{1}-\rho_{2}\right) F_{0}\left(Q R_{1}\right)+R_{2}^{3}\left(\rho_{2}-\rho_{s}\right) F_{0}\left(Q R_{2}\right)\right] \\
F_{0}(x) & =\frac{3}{x^{3}}(\sin x-x \cos x)
\end{aligned}
$$

Several particle shapes were used to calculate $P(Q)$, and the best fits were given by a spherical core-shell model with a Schultz distribution ${ }^{9,10}$ of particle sizes

$$
\begin{aligned}
f\left(R_{1}\right) & =\frac{(Z+1)^{Z+1} X^{Z} \exp [-(Z+1) X]}{\overline{R_{1}} \Gamma(Z+1)} \\
Z & =\frac{1-\left(\frac{\sigma}{\overline{R_{1}}}\right)^{2}}{\left(\frac{\sigma}{\overline{R_{1}}}\right)^{2}} \\
X & =\frac{R_{1}}{\overline{R_{2}}}
\end{aligned}
$$

where $\sigma^{2}$ is the variance of the distribution, $Z$ is the breadth parameter and $\rho_{1}, \rho_{2}$ are the core/shell SLDs.

Figure (7) shows the fit to the SANS data, using the parameters derived from the initial 
SAXS data ${ }^{11}$. It may be seen that the simulation differs from the SANS data by a substantial factor, thus illustrating the point made by Hayter and Penfold ${ }^{18}$ that the cross section is extremely sensitive to the particle dimensions $\left(d \Sigma / d \Omega \sim R^{6}\right)$, and that even an approximate calibration $( \pm 25 \%)$ is desirable to avoid such discrepancies. In principle, the SANS simulation should be different for the $\mathrm{H}_{2} \mathrm{O}$ - and $\mathrm{D}_{2} \mathrm{O}$-swollen micelles. However, Fulton et al., gave no quantitative estimate as to the location of the aqueous species, and assumed that the core (the probable location of the absorbed water) had the bulk (unswollen) PEO density. We have therefore calculated the core SLD on this basis. Although the different isotopes would have had the same SAXS contrast, it may be seen that the SANS patterns are quite different [fig. (7)].

Figs. (8) and (9) show fits to the SANS data using core-shell model and changing only the contrast between the $\mathrm{H}_{2} \mathrm{O}$ - and $\mathrm{D}_{2} \mathrm{O}$-swollen systems. The inner and outer radii are $\simeq 86 \AA$ and $\simeq 128 \AA$ respectively, with an aggregation number (i.e. the number of molecules per micelle) of $\mathrm{N}_{\mathrm{agg}} \simeq 83$, compared to $\mathrm{N}_{\mathrm{agg}} \simeq 120$ derived from the SAXS study, and $\mathrm{N}_{\mathrm{agg}} \simeq 3$ for the unswollen micelle. Thus, the basic overall picture remains the same as in the initial study, though the advantage of absolute calibration and the extra information provided by the contrast variation studies allows a more precise description of the system.

The SLDs for the core and shell respectively are 1.93 and $1.87 \times 10^{10} \mathrm{~cm}^{-2}$ (for $\mathrm{D}_{2} \mathrm{O}$ ) and 1.50 and $2.17 \times 10^{10} \mathrm{~cm}^{-2}$ (for $\mathrm{H}_{2} \mathrm{O}$-swollen micelles). These values may be compared with 2.12 and 0.7 and $3.36 \times 10^{10}$ for $\mathrm{CO}_{2}$, bulk PEO and PFOA respectively, indicating that there must be considerable mixing of the components in both regions. 
The shell SLD is higher when the micelle is swollen by $\mathrm{D}_{2} \mathrm{O}$, indicating that water swells not only the core but also the shell, which must therefore be penetrated by PEO in addition to $\mathrm{CO}_{2}$. The fact that the shell SLD is less for the $\mathrm{D}_{2} \mathrm{O}$ - swollen micelle as compared to the equivalent $\mathrm{H}_{2} \mathrm{O}$-swollen system is puzzling, though the $\mathrm{CO}_{2}$ solvent is saturated with water, and thus it is not certain that each sample has absorbed the same amount of fluid.

These comparisons indicate the extra information available from the combination of absolute calibration and isotopic labelling, though it is still insufficient to independently determine all the details of the micelle structure (partitioning of water $/ \mathrm{CO}_{2}$ between the core/shell etc.). It should be noted that the combination of absolute SAXS and SANS data, each highlighting different features of the system via the particular contrast factors, would provide an even more precise description of the system. We are currently exploring the possibility of combining these techniques on the same set of micelle-forming amphiphiles (e.g. polystyrene-PFOA blockcopolymers). These systems were described in an initial publication $^{2}$, and will also be the subject of future paper containing detailed model simulations.

\section{ACKNOWLEDGEMENTS}

Research supported by the Division of Materials Sciences, U. S. Department of Energy under contract No. DE-AC05-840R21400 with Lockheed Martin Energy Systems Inc., by the National Science Foundation (J. M. DeSimone, Presidential Faculty Fellow, 19931997), and also by the Consortium for Polymeric Materials Synthesis at the University of North Carolina, sponsored by Dupont, Air Products and Chemicals, Hoechst-Celanese, Eastman Chemical, B. F. Goodrich, Xerox, Bayer and General Electric. 


\section{REFERENCES}

(1). J. M. 'DeSimone, Z. Guan, C. S. Elsberni, Science, 257 (1992) 945.

(2). D. Canelas, D. E. Betts, J. B. McLain, E. T. Samulski, J. M. DeSimone, J. D. Londono and G. D. Wignall, Science, (submitted).

(3). J. B. McLain, J. D. Londono, T. J. Romack, D. P. Canelas, D. E. Betts, E. T Samulski. J. M. DeSimone and G. D. Wignall, Macromolecules, (submitted).

(4). J. M. DeSimone, E. E. Maury, Y. Z. Menceloglu, J. B. McClain, T. R. Romack, Science, 265 (1994) 356-59.

(5). Z. Guan, J. M. DeSimone, Macromolecules, 27 (1994) 5527.

(6). K. A. Shaffer, J. M. DeSimone, Trends in Polymer Science, (1995) in press.

(7). G. D. Wignall, Chapter 7, p. 313 in "The Physical Properties of Polymers", ed. J. E. Mark, ACS Books (1993).

(8). G. D. Wignall, p. 112 in Encyclopedia of Polymer Science and Engineering, Second Edition, Vol. 10, John Wiley \& Sons, Inc., New York, (1987).

(9). E. Caponetti, and R. Triolo, Adv. Colloid and Interface Sci., 32 (1990) 235.

(10) L. J. Magid, Colloids and Surfaces, Elsevier, Amsterdam, 19 (1986) 129.

(11) J. L. Fulton, D. M. Pfund, J. B. McLain, T. J. Romack, E. E. Maury, J. R. Combes and M. Capel, Langmuir, in press

(12) D. M. Pfund, T. S. Zemanian, J. C. Linehan, J. F. Fulton and C. R. Yonker, J. Phys. Chem., 98 (1994) 846.

(13) E. W. Kaler, J. F. Billman, J. L. Fulton, and R. D. Smith, J. Phys. Chem., 95 (1991) 458. 
(14) W. C. Koehler, Physica (Utrecht), 137B (1986) 320.

(15) G. D. Wignall and F. S. Bates, J. Appl. Cryst., 20 (1986) 28.

(16) J. D. Londono, V. M. Shah, G. D. Wignall, H. D. Cochran and P. R. Bienkowski, J. Chem. Phys., 99(1) (1993) 466.

(17) Neutron, X-Ray and Light Scattering, ed. P. Lindner and T. Zemb, North-Holland Delta Series, Elsevier, New York, (1991).

(18) H. Fujita, Polymer Solutions", Elsevier, Amsterdam, p. 44, (1990).

(19) J. B. Hayter and J. Penfold, Colloid and Polym. Sci., 261 (1983) 1022.

\begin{tabular}{|c|c|c|c|c||}
\hline Polymer & $\begin{array}{c}10^{-3} \mathrm{M} \\
(\mathrm{g} / \mathrm{mol})\end{array}$ & $\begin{array}{c}10^{4} \mathrm{~A}_{2} \\
\left(\mathrm{~cm}^{3} \mathrm{~g}^{-2} \mathrm{~mol}\right)\end{array}$ & $\begin{array}{c}\mathrm{R}_{\mathrm{g}}(\AA) \\
\mathrm{R}_{\mathrm{g}} / \mathrm{M}^{1 / 2} \\
\left(\AA \mathrm{g}^{-0.5}\right)\end{array}$ \\
\hline HMW-PFOA & $1000 \pm 400$ & $0.25 \pm 0.05$ & $100 \pm 9$ & $0.10 \pm 0.02$ \\
\hline LMW-PFOA & $110 \pm 20$ & $0.6 \pm 0.1$ & $34 \pm 5$ & $0.10 \pm 0.02$ \\
\hline HFPPO & $13 \pm 1$ & $0.0 \pm 0.2$ & $30-37$ &. \\
\hline
\end{tabular}

Table 1 - Molecular weight $(M)$, second virial coefficient $\left(A_{2}\right)$, radius of gyration $\left(R_{g}\right)$, and $\mathrm{R}_{\mathrm{g}} / \mathrm{M}^{1 / 2}$ for PFOA and fluorinated polypropylene oxides. 


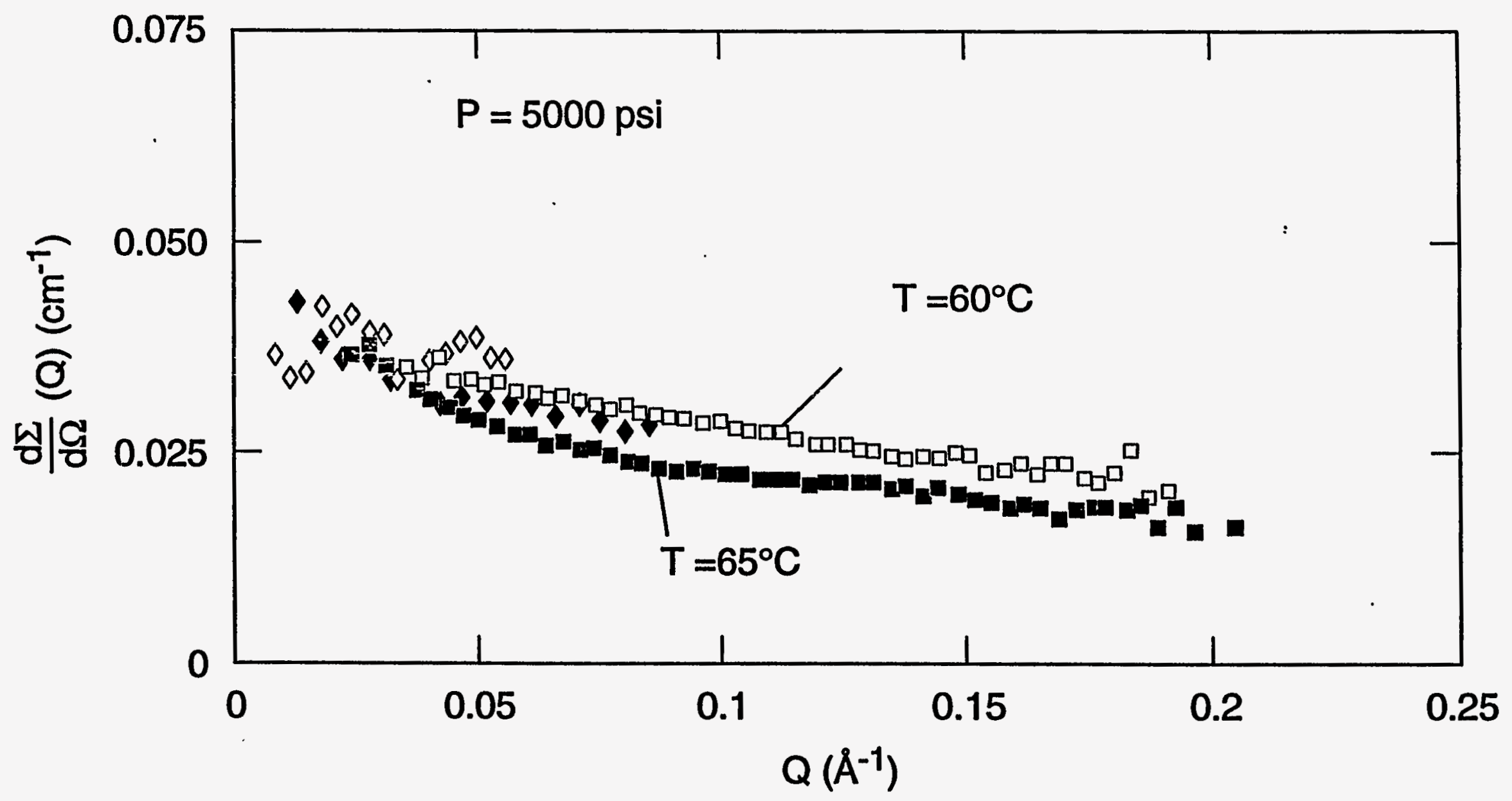

BACKGROUND SCATTERING FROM $\mathrm{CO}_{2}$ BLANKS AT $\mathrm{T}=60^{\circ} \mathrm{C}$ AND $\mathrm{T}=65^{\circ} \mathrm{C}$ 
PFOA in $\mathrm{CO}_{2}$

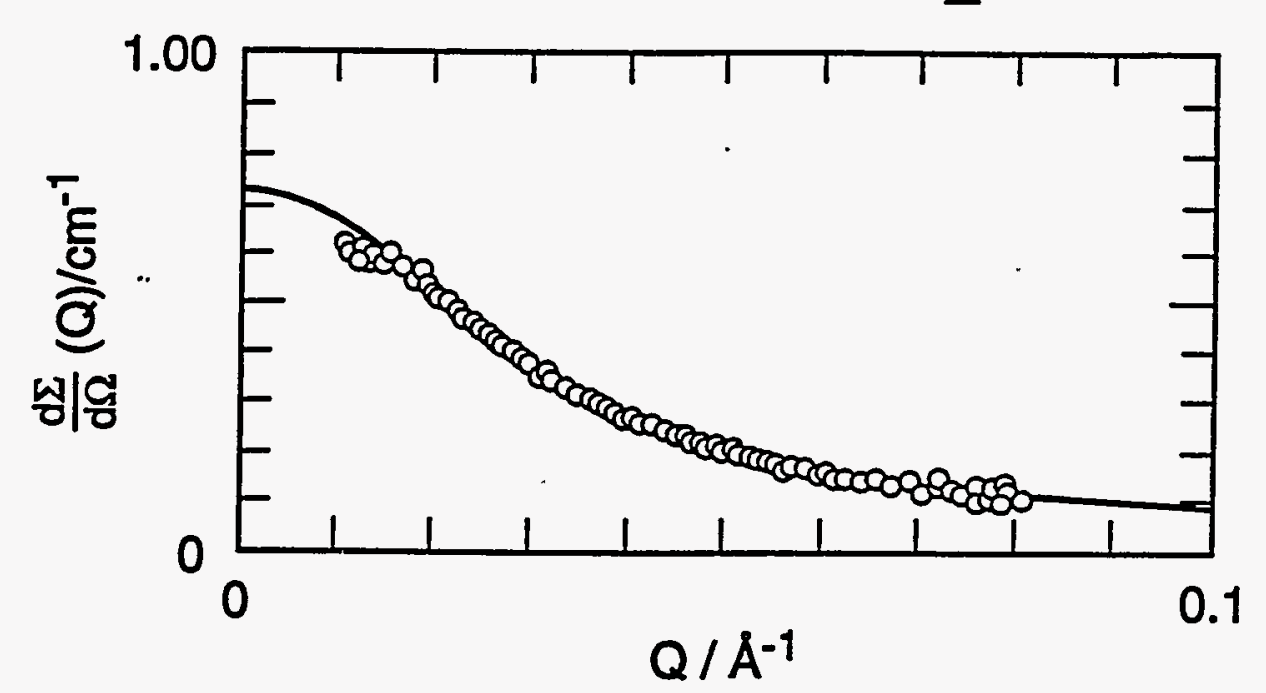

(2)

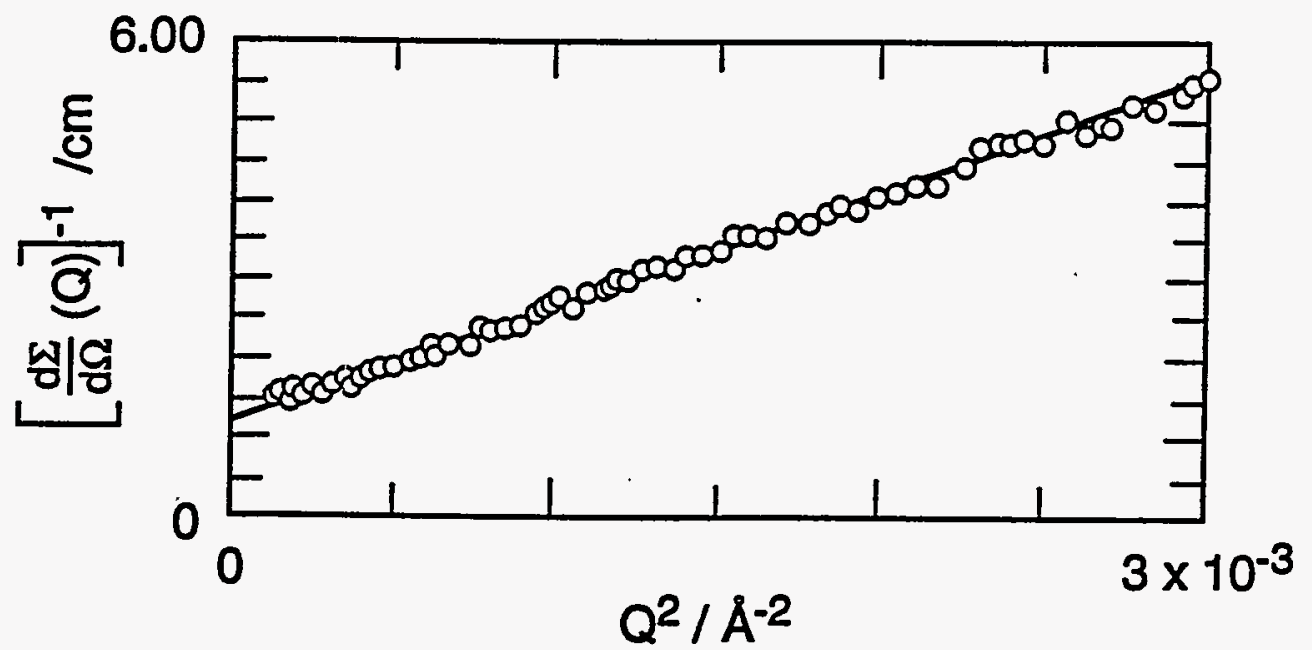

DEBYE AND ZIMM FITS TO SANS DATA. 10\% (W/N) HIGH MOLECULAR WEIGHT POLYFLUOROOCTYL ACRYLATE IN SUPERCRITICAL $\mathrm{CO}_{2}$
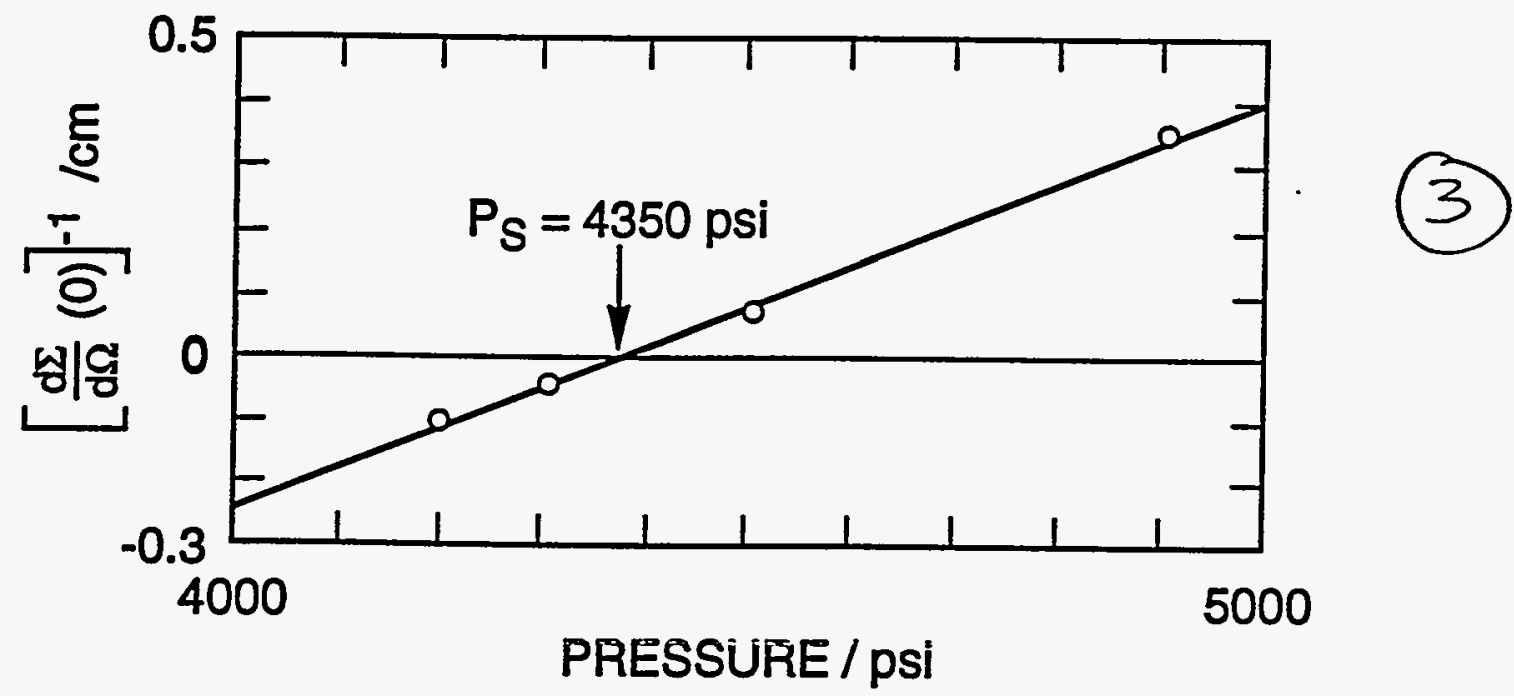

SOLUBILITY DETERMINATION USING SANS. $3 \%$ (WN) POLYFLUOOCTYL ACRYLATE (PFOA) IN CO 2 AT $65^{\circ}$ 
FLUORINATED POLYPROPYLENE OXIDE $\left(\mathrm{C}_{3} \mathrm{~F}_{6}\right.$ O)
\[ \mathrm{INO}_{2} \]
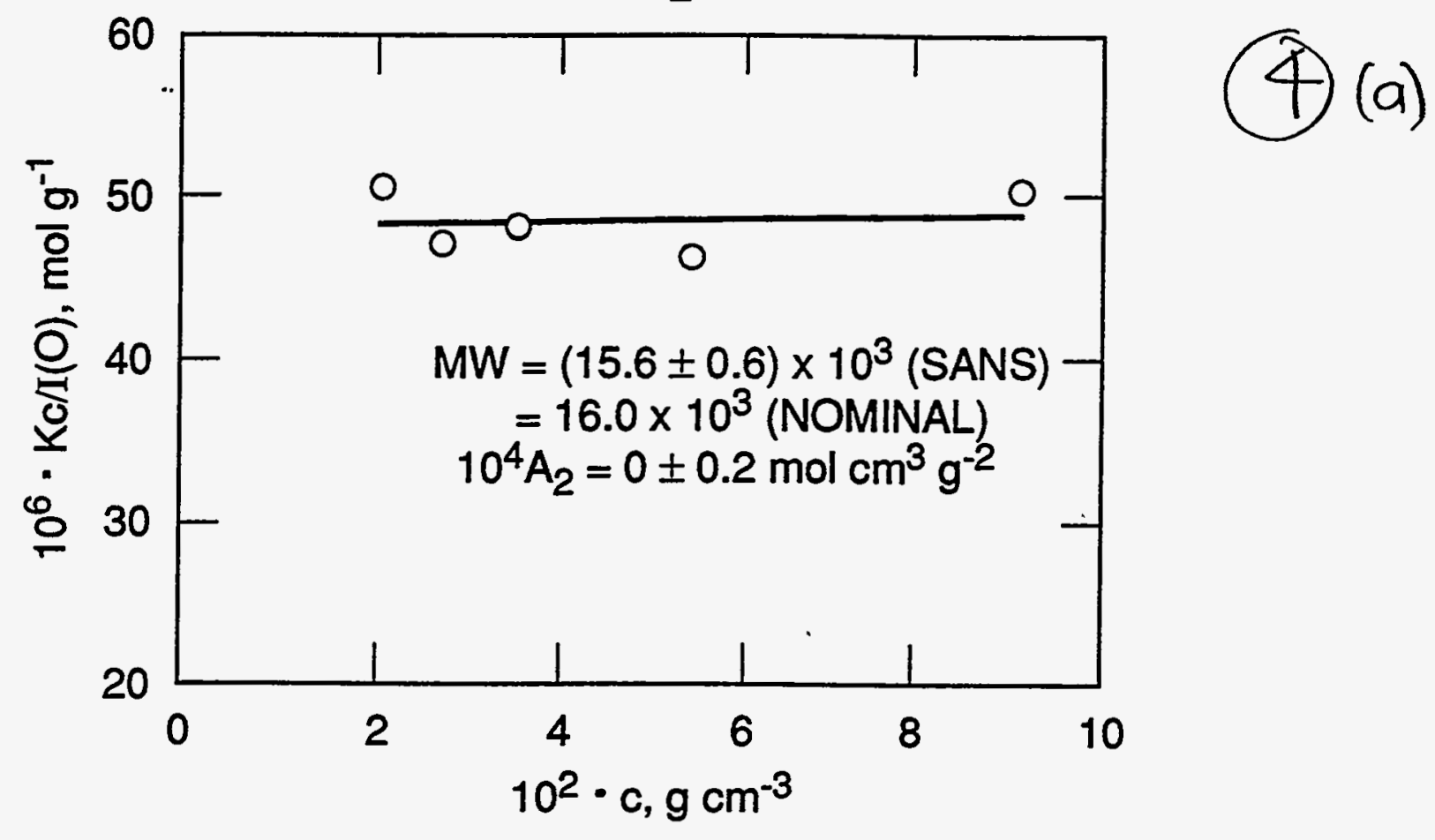

$4(b)$

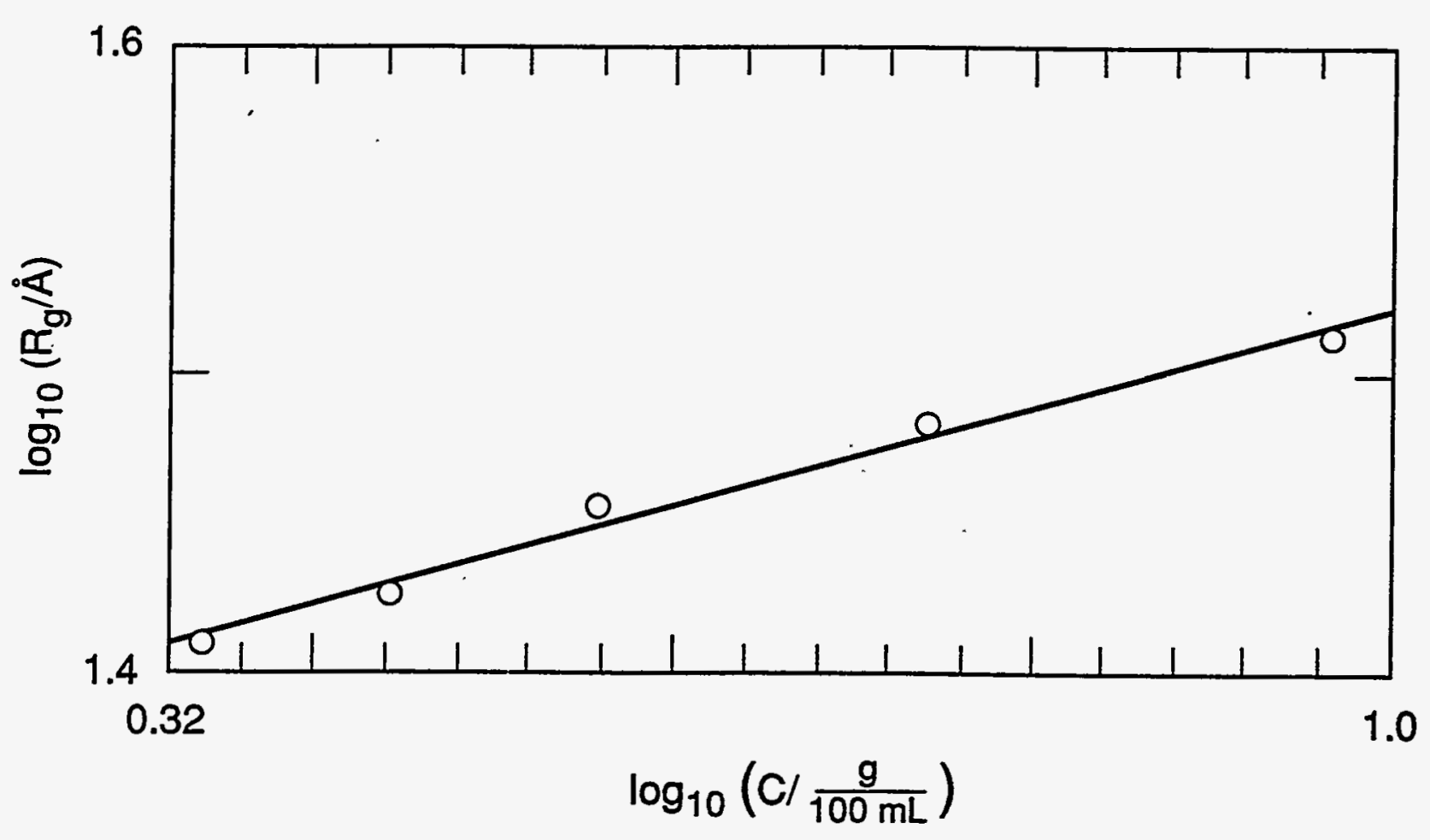

RADIUS OF GYRATION VARIES SYSTEMATICALLY WITH CONCENTRATION 


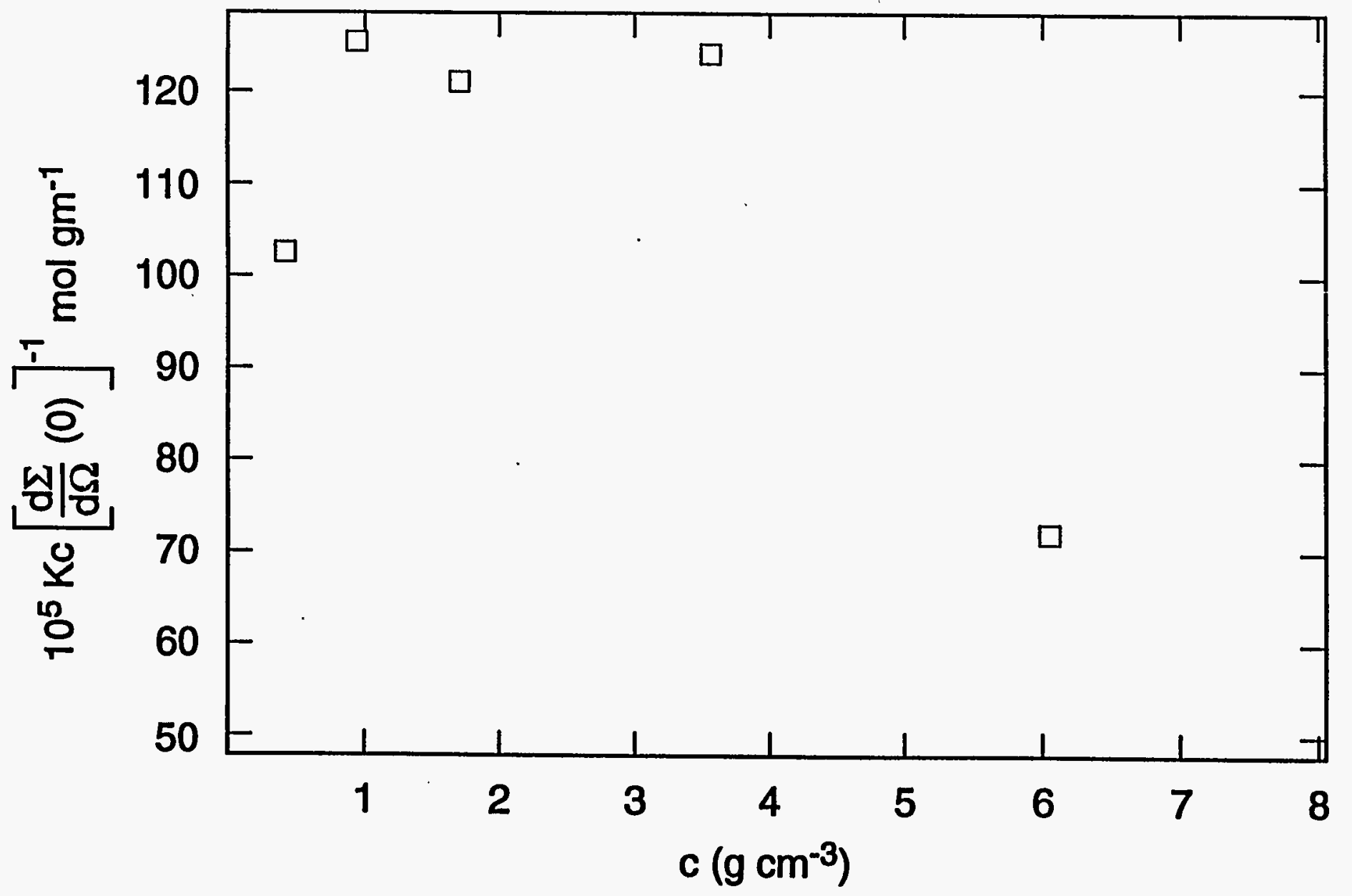

INVERSE $(Q=0)$ CROSS SECTION AS A FUNCTION OF THE CONCENTRATION OF POLYDIMETHYLSILOXANE IN $\mathrm{CO}_{2}$ 


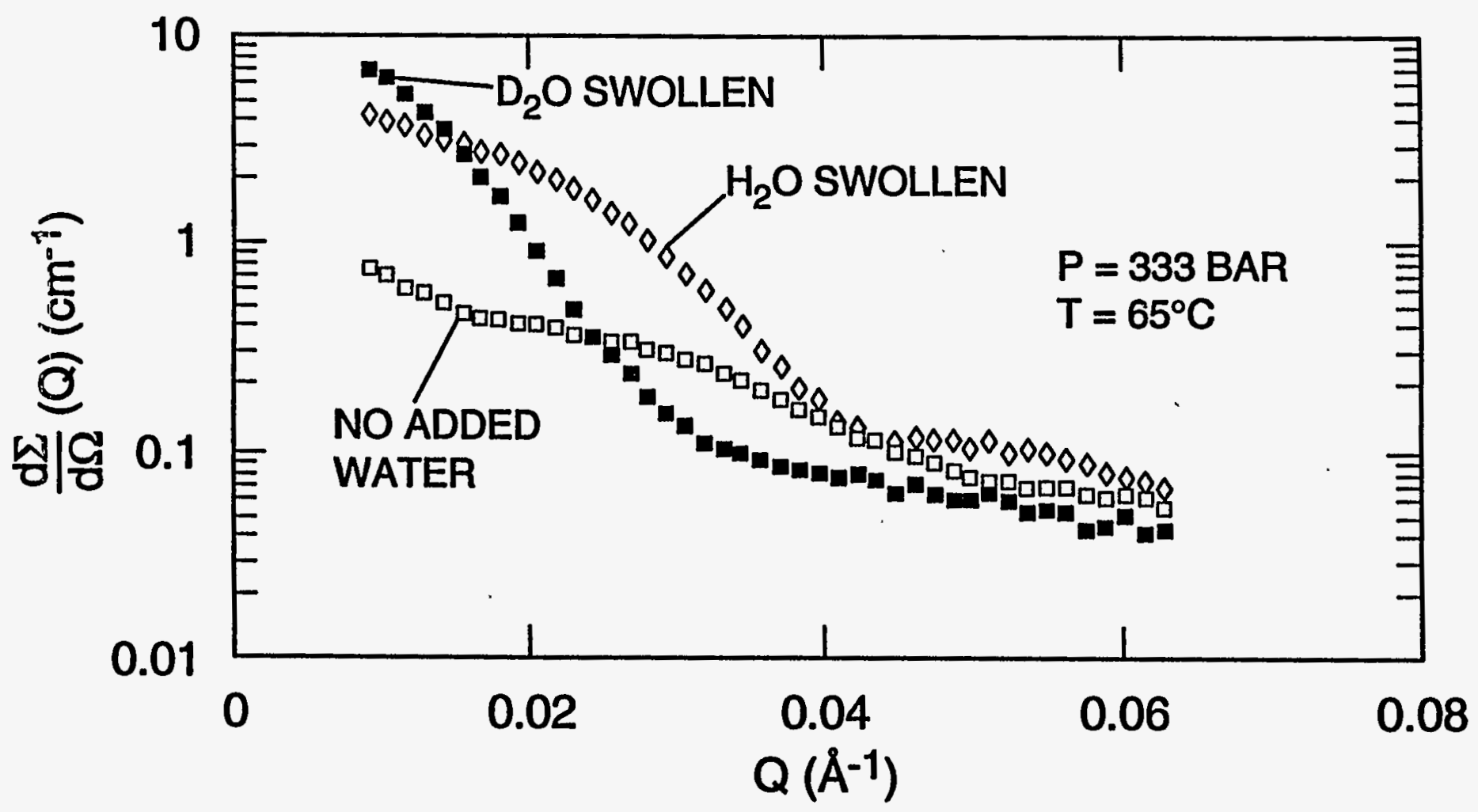

\section{$\frac{\mathrm{d} \Sigma}{\mathrm{d} \Omega}$ (Q) FOR PFOA-g-PEO GRAFT COPOLYMER IN $\mathrm{CO}_{2}$ BEFORE AND AFTER SWELLING WITH $\mathrm{H}_{2} \mathrm{O}$ AND $\mathrm{D}_{2} \mathrm{O}$}




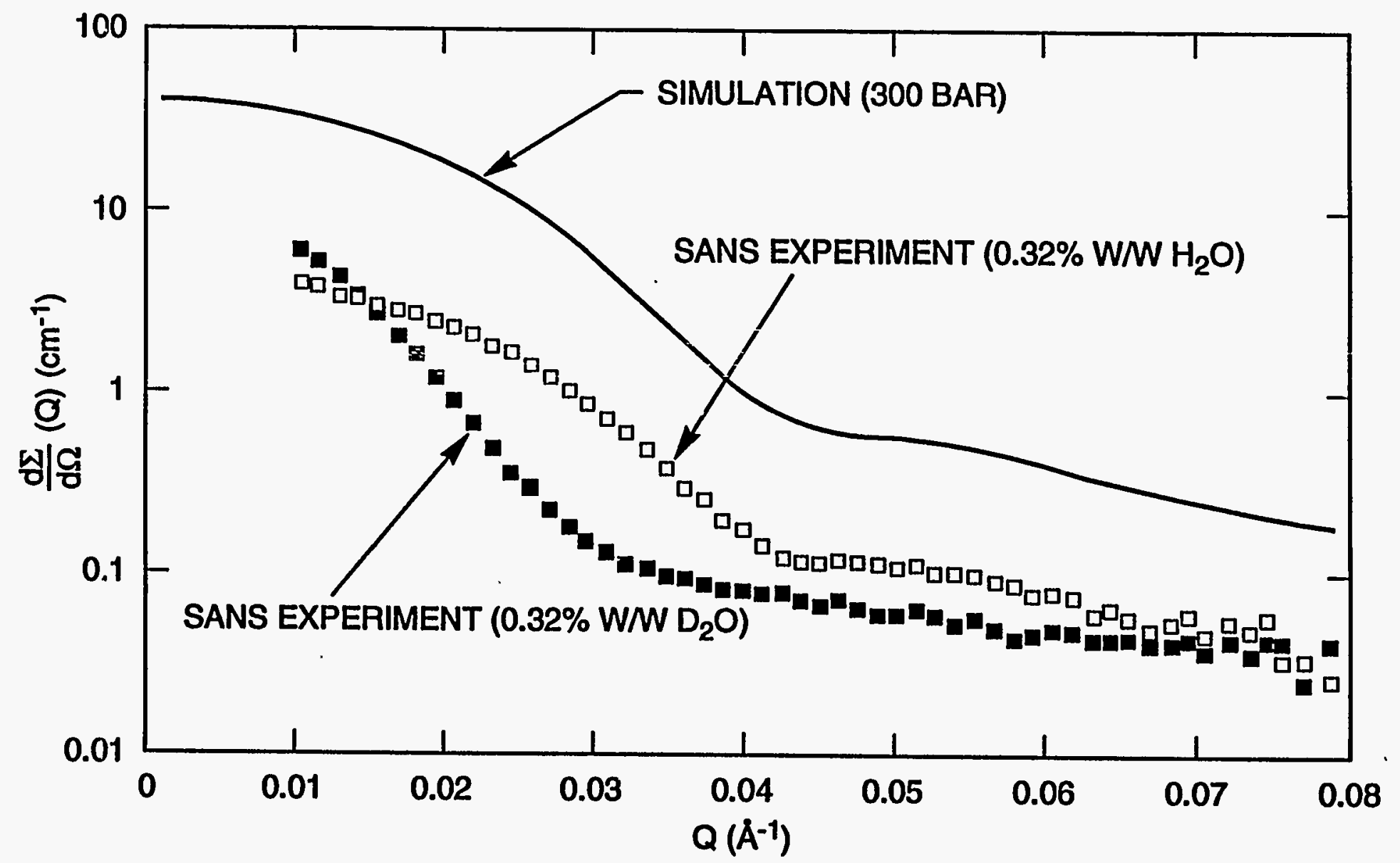

SANS DATA FOR 1.9\% PEO-GRAFT COPOLYMER IN SUPERCRITICAL $\mathrm{CO}_{2}$ (SATURATED WITH WATER) COMPARED TO SIMULATION USING PARAMETERS FROM FULTON et al., LANGMUIR,1995 


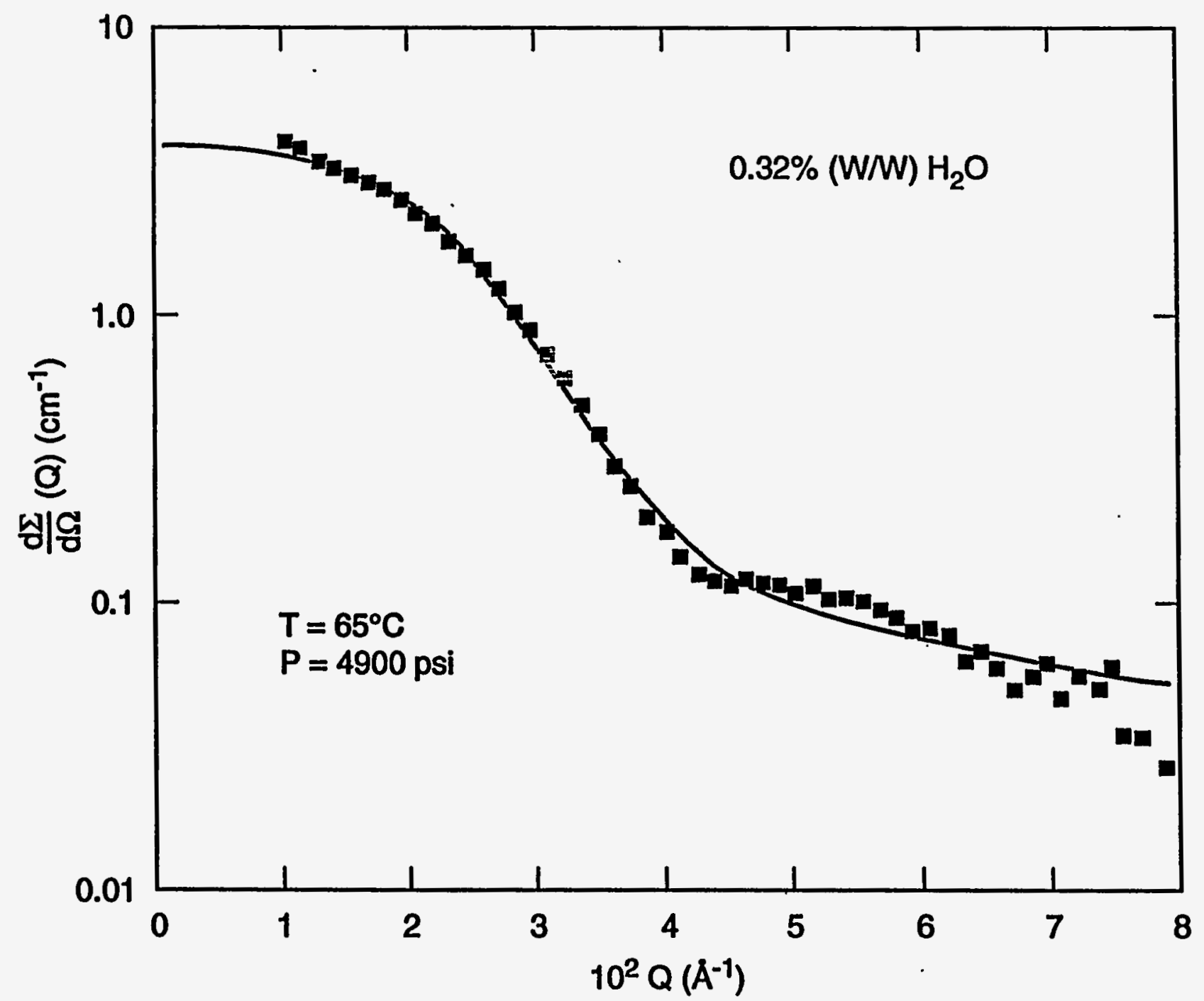

SANS DATA FROM 1.9\% (W/V) PFOA-PEO GRAFT COPOLYMER IN $\mathrm{H}_{2} \mathrm{O}-\mathrm{SATURATED} \mathrm{SUPERCRITICAL} \mathrm{CO}_{2}$ COMPARED TO POLYDISPERSE CORE-SHELL MODEL 


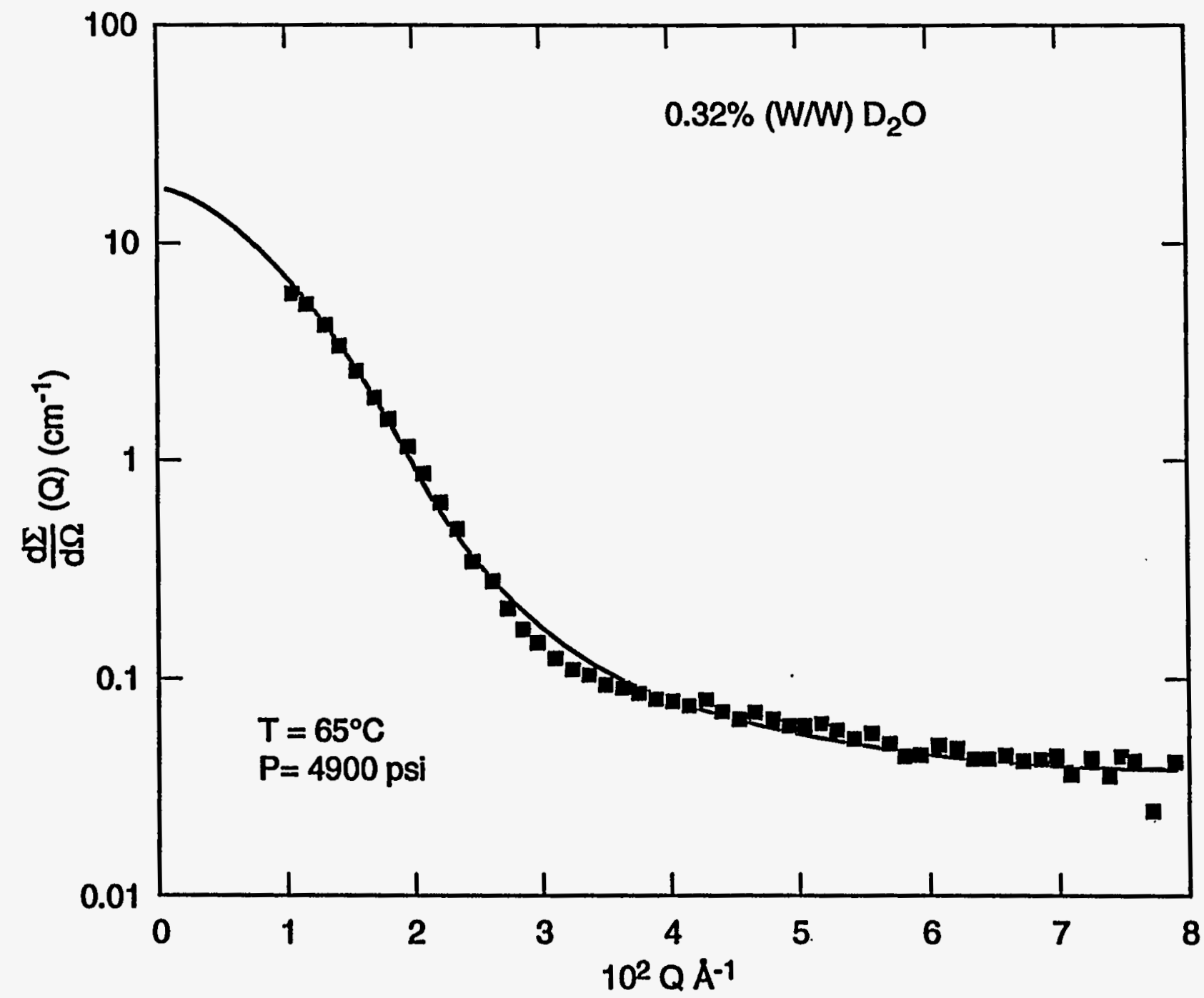

SANS DATA FROM 1.9\% (W/V) PFOA-PEO GRAFT COPOLYMER IN $\mathrm{D}_{2} \mathrm{O}$-SATURATED SUPERCRITICAL $\mathrm{CO}_{2}$ COMPARED TO POLYDISPERSE CORE-SHELL MODEL 